\title{
Development of magnetic flux leakage device as a non- destructive method for structural reinforcement detection
}

\author{
๑Ö. Bektaş®凶, ๑Y.C. Kurban ${ }^{\mathrm{b}}$, ®B. Özboylan ${ }^{\mathrm{c}}$ \\ a. Sivas Cumhuriyet University, Engineering Faculty, Geophysical Engineering Department, (Sivas, Turkey) \\ b. Eskişehir Osmangazi University, Engineering and Architectural Faculty, Geological Eng. Dept., (Eskişehir, Turkey) \\ c. Progida OLAM Group Company, (Samsun, Turkey) \\ 凶: obektas@cumhuriyet.edu.tr
}

Received 27 January 2021

Accepted 21 July 2021

Available on line 22 February 2022

\begin{abstract}
Non-destructive measurement techniques are used to identify engineering construction components without causing any negative effects on their use as construction components in the future. Contrary to this, conventional techniques cause damage to the structure. The magnetic flux leakage (MFL) method is a non-destructive test technique commonly used to assess the physical status of construction materials. Within the framework of this study a magnetic flux leakage device was produced to detect the properties of reinforced concrete construction elements. The produced magnetic flux leakage device was used for measurements in 4 different test systems created in the laboratory environment and the results were interpreted. Thus, it was revealed that the detection of reinforcement in structures can be performed more rapidly and without damage with the MFL method.
\end{abstract}

KEYWORDS: Magnetic flux leakage method; Concrete; Metal reinforcement; Rebar.

Citation/Citar como: Bektaş, Ö.; Kurban, Y.C.; Özboylan, B. (2022) Development of magnetic flux leakage device as a nondestructive method for structural reinforcement detection. Mater. Construcc. 72 [345], e273. https://doi.org/10.3989/mc.2022.02421.

RESUMEN: Desarrollo de un dispositivo de fuga de flujo magnético como método no destructivo para la detección de refuerzos estructurales. Las técnicas de medición no destructivas se utilizan para identificar componentes de construcción de ingeniería sin causar ningún efecto negativo en su uso futuro como componentes de construcción. Por el contrario, las técnicas convencionales sí provocan daños en la estructura. El método de fuga de flujo magnético (MFL) es una técnica no destructiva que se usa comúnmente para evaluar el estado físico de los materiales de construcción. En el marco de este estudio se produjo un dispositivo de fuga de flujo magnético para detectar las propiedades de los elementos constructivos de hormigón armado. El dispositivo de fuga de flujo magnético producido se utilizó para mediciones en 4 sistemas de prueba diferentes creados en laboratorio y se interpretaron los resultados obtenidos. Así, se reveló que la detección de armaduras en estructuras se puede realizar de forma más rápida y sin daños con el método MFL.

PALABRAS CLAVE: Método de fuga de flujo magnético; Hormigón; Refuerzo de metal; Barras de refuerzo.

Copyright: (C2022 CSIC. This is an open-access article distributed under the terms of the Creative Commons Attribution 4.0 International (CC BY 4.0) License. 


\section{INTRODUCTION}

Nondestructive test techniques (NDT) represent a variety of techniques like flux leakage method, building radar, radiographic methods, acoustic methods and sonic methods used to investigate and assess materials and structures. Nondestructive testing has an important place in determining the strength properties of natural stone and concrete used in modern construction and historical buildings (1-10). Contrary to this, some test techniques cause damage to the structure and as a result only controlled numbers of test samples can be taken. Nondestructive test systems are generally used to identify the material properties or to show the presence of abnormalities in a material. In other words, the technique used determines the physical properties of the material or changes occurring in the physical properties. There are a variety of electromagnetic NDT techniques available to assess metallic materials and assemblies. These include magnetic flux leakage (MFL) methods, puls magnetic flux leakage (PMFL) method, eddy current (EC) method, puls eddy current (PEC) method, magnetic particle test (MPT) method, etc. These methods examine the interaction between conductive samples to be investigated and electromagnetic fields (11). NDT methods come to the agenda for investigation of reinforced concrete structures without harming the region to be researched. During building inspections, it is important to identify the steel elements, grout thickness, diameter and corrosion status of reinforcement within the columns and walls of a building. NDT are performed without causing any disruption to the structure and ensure safe use of engineering structures. There are a variety of NDT available to identify steel elements within concrete and to assess concrete structures.

MFL is commonly used to detect elements made of ferromagnetic material without damaging. It is a nondestructive test method that was firstly developed to investigate concrete bridges at the end of the 1970s and has been further developed through the years. Later it was used to identify surface and subsurface defects in structures like underground pipelines, floors of petrol storage tanks and railway lines etc. and additionally to identify defects in symmetric components like steel rods, pipes and tubes (12).

The MFL method was investigated by many researchers and successful results were obtained. $\mathrm{Li}$ et al. (13) discussed results for magnetic field distribution characteristics of finite elements (FEM) of fractured surfaces with a variety of widths (fracture depth $0.2 \mathrm{~mm}$, width interval $0.02-1.00 \mathrm{~mm}$ ). In conclusion, they stated that the fracture width and distance between surface and sensor will affect the signal. Additionally, they considered effects on peak-peak values for normal components of distance parameters between different surfaces and sensor in the magnetic flux leakage test. They stated the effect may be applied to assess surface breaking cracks with different widths and depths and that using alternative current (AC) field magnetization provided an idea to correct the tips of narrow sharp fractures. Ramirez et al. (14) performed specially designed experimental studies to assess the ability of an MFLbased machine to distinguish defects in the top and bottom of tanks. Some studies consider this type of top and bottom classification to be possible, but in this study, the experimental results designed for this purpose showed that this type of differentiation between signals from upper and lower defects may not be possible using standard MFL-based techniques. Sun and Kang (15) proposed a new MFL principle and technique based on creating a background magnetic field near to zero for the first time based on magnetic compression effect (MCE) analysis in available MFL applications. They determined the feasibility of the proposed principle with simulations and experiments. They determined that contact probes applying the proposed MFL principle may prevent severe wear and could be applied to pipes at high temperatures. Tsukada et al. (16) used magnetic flux leakage studies to nondestructively assess spot welding and compared the sturdiness of spot welding, commonly used to join metal plates, with destructive and nondestructive methods. They developed an MFL system using a magnetic resistance (MR) sensor to examine spot welds without destruction. In the study they determined a linear correlation between the nondestructive magnetic flux leakage test and destructive shear tests. Rao (12) explained the operating principle, capability, applications and limitations of the MFL technique to detect defects in ferromagnetic objects. The topics related to parameters affecting MFL signals and theoretical modelling with analyses were discussed. They emphasized the latest developments in MFL technology for automatic detection and determining the dimensions of defects. Göktepe and Perin (17) aimed to image steel elements within reinforced concrete structures using the MFL technique. The method used was completed nondestructively. Within the scope of the study, the parallel and perpendicular measurements were compared and they identified that the practical perpendicular measurement provided much better results. Loa and Nakagawa (18) investigated the EC and MFL methods to identify corrosion damage in rebar connecting concrete barrier rails with road decks in bridge structures. These two methods were applied to rebar with and without artificial defects causing $25 \%$ and $50 \%$ material loss and results were compared. In conclusion, both techniques were determined to easily identify defects from 2.5 " $(63.5 \mathrm{~mm})$ distance. Shi et al. (19) performed studies about the theory and application of the MLF method to determine pipe lines. They discussed quantitative analysis of the MFL method as the key point in detecting magnetic 
flux leakage signals. Additionally, they analyzed the advantages and disadvantages of different detection methods. Wu et al. (20) proposed a new composite MFL method using alternative magnetic field induction to detect cracks in pipelines. The results of the study showed that two vertical detection signals could be differentiated with a simple low-pass filter and thus they stated that only one scan to overcome the blind spot problem in traditional MFL detectors could obtain flaw characteristics in axial and environmental directions. Okolo (11) completed magnetic flux leakage distribution modeling for detection and characterization of hairline cracks and performed experimental studies. The results of this study determined the detection and characterization of MFL distribution caused by hairline cracks with rectangular surface and distant surface. Wilcke et al. (21) studied simple applications of the magnetic flux leakage technique to concrete structures. Due to pre-stressed structural reinforcement being sensitive to corrosion cracking, they stated the need for detailed research of fractures within steel elements after stressing. For this reason, the nondestructive magnetic flux leakage measurement technique may be applied even within cladding tubes. Antipov and Markov (22) researched the traditional MFL method for speed limitations in railroad inspection and overcoming these limitations. They applied two different methods to research the dependence of flux leakage data on measurement speed. The first method performed 3D computer simulation of interactions between a fixed rail and mobile magnetizing system and the second method used measurement clusters created by an experimental system comprising mobile sensors and artificial defects created along the rail. In conclusion, the defects at the center of the rail head could be identified at speeds above $80 \mathrm{~km} / \mathrm{h}$ and they stated the distance between the poles of the magnetizing system should be more than $3 \mathrm{~m}$ or some alternative like MFL remote field analysis should be used. Sadr and Okhovat (23) studied MFL signals for detection of defects in ferromagnetic materials. They used histograms to eliminate effect of defects. Myakushev et. al. (24) investigated Magnetic flux leakage (MFL) method for nondestructive testing of pre-stressed steel reinforcement strands and discussed magnetic, measuring systems and design principles.

When previous studies related to the MFL method are investigated, it appears the MFL method is generally used to determine defects in pipelines and rail systems. Additionally, use to detect corrosion occurring in reinforcement comprising structural elements is encountered. Considering the previous studies, in this study, device for the nondestructive test technique of MFL method was produced and used for detection of reinforcement comprising structural elements in buildings. Thus, important results are reached about detection reinforcement with the MFL method.

\section{DESIGN AND PROTOTYPE PREPARATION}

In order to perform MFL measurements, a transmitter coil, receiver coil, and transmitter and receiving coil electronic systems are required. For this reason, within the scope of the study all relevant pieces were designed and produced. For the core of the transmitter coil used a 'soft iron core' bent into a U shape (Figure 1). Above the core, bent into appropriate shape, $0.55 \mathrm{~mm}$ thick enamel-covered copper wire was used to create the transmitter coil.

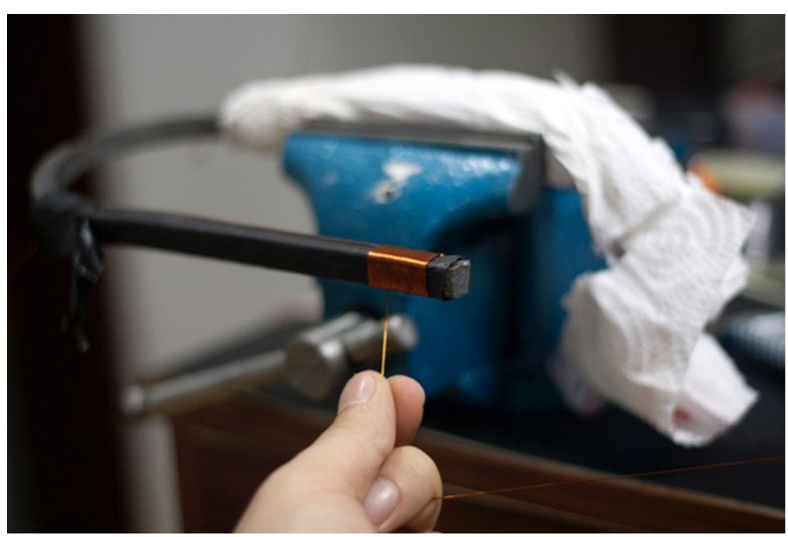

FIGURE 1. Preparation stage of MFL transmitter coil.

After preparing the transmitter coil, frequency response graphs were prepared with the aim of determining suitable operating frequencies. When preparing the frequency response graphs, a calibrated function generator output was applied to the transmitter coil with sinus waves at different frequencies. The current induced in the receiver coil due to the current applied to the transmitter coil was recorded with the aid of an oscilloscope. In this way, the response of the designed system at different frequencies was obtained and a frequency-amplitude graph was plotted (Figure 2).

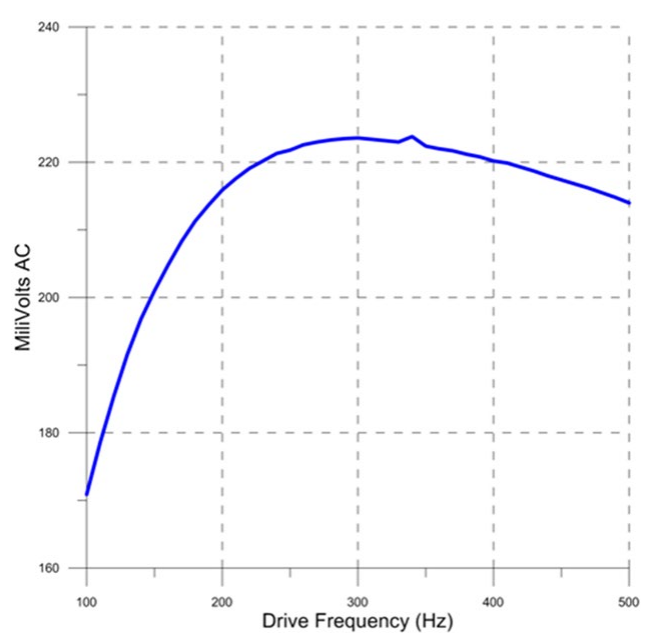

FigURE 2. Frequency - amplitude graph of sensor unit. 
As seen on the graph in Figure 2, the system was observed to reach highest point at amplitudes in the $\sim 220-400 \mathrm{~Hz}$ band, so for this reason the operating frequency was chosen as $300 \mathrm{~Hz}$. After this stage, all prepared electronic device were designed in accordance with $300 \mathrm{~Hz}$ center frequency. The designed transmitter circuit was produced using a microprocessor-controlled signal generator so the transmitter frequency would remain stable. The signal amplitude was set to $48 \mathrm{VAC}$.

The receiver coil was created with a core containing a high permeability 'soft iron core', like the transmitter coil, isolated with enamel-covered copper wire. The receiver section may be affected by the electromagnetic field measured in the receiver coil and in the operating environment. For this reason, a capacitor connecting the receiver coil was matched to the transmitting frequency and attempts were made to suppress the effects of signals due to other parts of the electromagnetic spectrum on the coil. The photograph of the receiver and transmitter coils is shown in Figure 3.

Receiver and transmitter coil connections used co-axial cables with the aim of minimizing electromagnetic noise and preserving the signal quality and were ready to connect to electronic cards. The tips of the cables from the coils had appropriate connec-

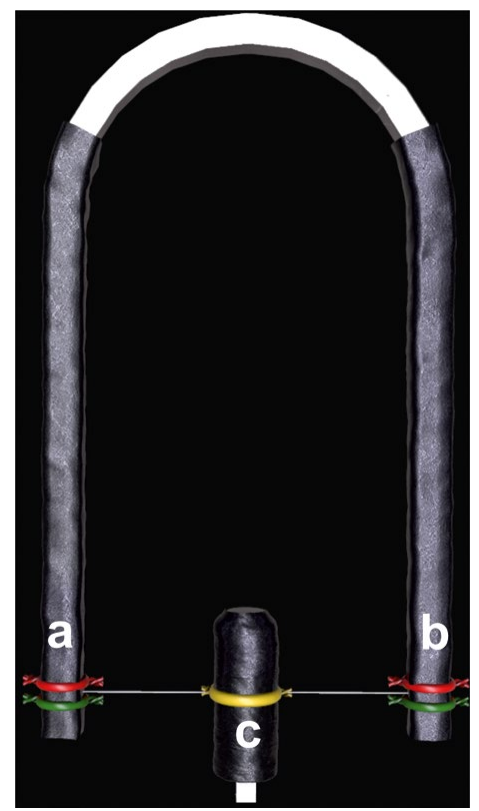

FIGURE 3. Receiver and transmitter coils (a) transmitter 1 (b) transmitter 2 (c) receiver (first prototype). tors fitted. Electrical parameters of the receiving and transmitter coils are given in Table 1.

The electronic system to induce an electromagnetic field in the transmitter coil and to record the current induced in the receiver coil was prepared and tested in the laboratory environment. With this aim, an oscillator producing a signal at the desired frequency, an amplifier to increase this signal and sent it to the transmitter coil and electronic system to increase and filter the current induced in the receiver coil were prepared. The block schema is shown in Figure 4.

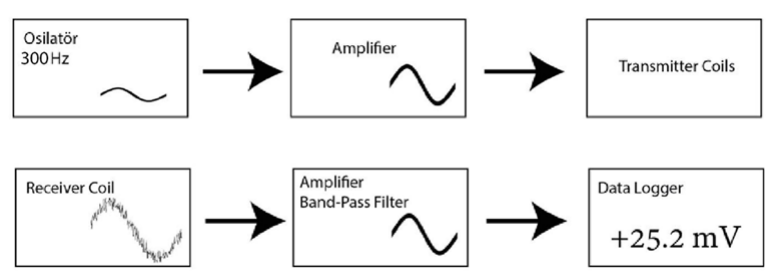

FiguRE 4. Block diagram of the electronic system.

The signal amplitude sent to the transmitter coil through the electronic system is adjustable. After the signal induced in the receiver coil is amplified and filtered, it may be read as peak to peak amplitude in millivolts. The electronic system was mounted within a plastic box (Figure 5a,b); in this way the electronic circuits comprised as system that could work together. In our system, we used ATMEGA 328 low power, CMOS 8-bit microcontroller from Microchip Company and OP-07 Ultralow Offset Voltage Operational Amplifier from Analog Devices for transmitter waveform generation, then fed this signal to transmitter antenna using TDA 8932 D-Class audio amplifier IC from NXP company. Receiver part of electronics consist of receiver coil, AD524 Precision Instrumentation Amplifier from Analog Devices and UAF42 Universal Active Filter From Burr-Brown company followed by OP-07 Ultralow Offset Voltage Operational Amplifier from Analog Devices. Fluke 289 multimeter used to measure filtered signal amplitude. All system designed to work at 12 Volt direct current power supply.

After test measurements in the laboratory, the transmitter and receiver coils were placed in a plastic box with no metal connection elements used so as not to affect the system. Connecting cables were isolated with protective tape (Figure 5a). The prepared device created an electromagnetic field with $300 \mathrm{~Hz}$

TABLE 1. Measured electrical and coil parameters of the receiving and transmitter coils.

\begin{tabular}{ccccc}
\hline & Resistance & Impedance & Diameter $(\mathrm{mm})$ & Number of windings \\
\hline Receiver & $619.9 \Omega$ & $30.5 \mu \mathrm{H}$ & 25 & 1200 \\
\hline Transmitter & $2.1 \Omega$ & $200 \mu \mathrm{H}$ & 8 & 350 \\
\hline
\end{tabular}




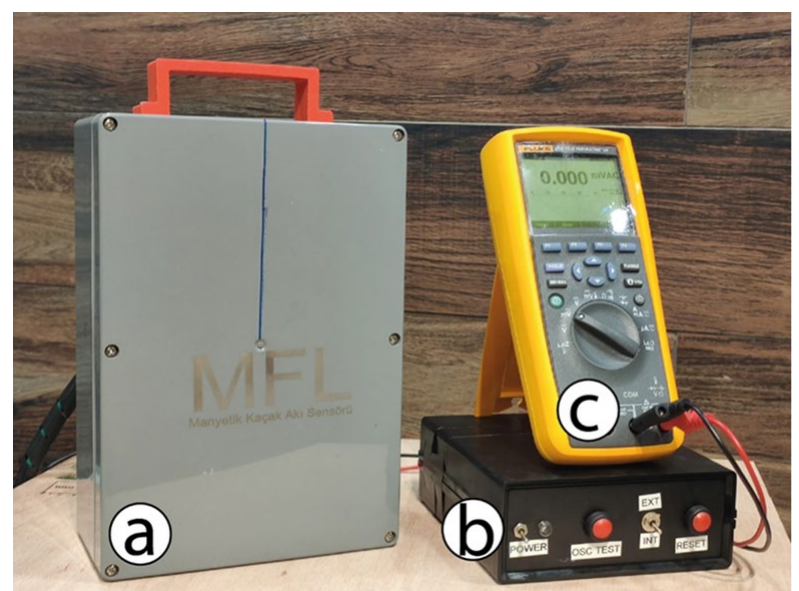

FiguRE 5. Designed measurement system, (a) Magnetic Flux leakage sensor of receiver - transmitter units, (b) Electronic control unit, (c) Multimeter.

frequency through the transmitter electronics and transmitter coil. The receiver coil was placed on a symmetric axis to the transmitter coil (Figure 3). The electromagnetic field induced by the transmitter intensified in the high-permeability receiver core and created a potential difference in receiver coil with amplitude directly proportional to the induced field in the enamel-coated copper wire around the core. The characteristics of the coils and distances between them were set to provide minimum amplitude in situations where there was no metal close to the sensor. When high-permeability metal is placed close to the sensor, the magnetic flux intensifying in the receiver coil core increases; hence, the potential differences due to the induction increases in direct proportion. These potential differences in the receiver coil were read at measurements in millivolts with the aid of a multimeter after passing through analog conditioners as shown in the flow diagram in Figure 4 . The obtained values may be presented as two-dimensional graphs linked to distance or spatially on a grid.

\section{TEST MEASUREMENTS}

Four different experimental systems were created to test the produced MFL device.

\subsection{Test system 1}

The first test system included 7 ferromagnetic materials within a $90 \times 60 \mathrm{~cm}$ area as shown in Figure 6 . The depth of ferromagnetic materials are at $2 \mathrm{~cm}$ from the top of the test systems 1 .

In the first test system the profile intervals were 10 $\mathrm{cm}$ and the point intervals were $1 \mathrm{~cm}$ with measurements performed with the produced magnetic flux leakage device (Figure 7).

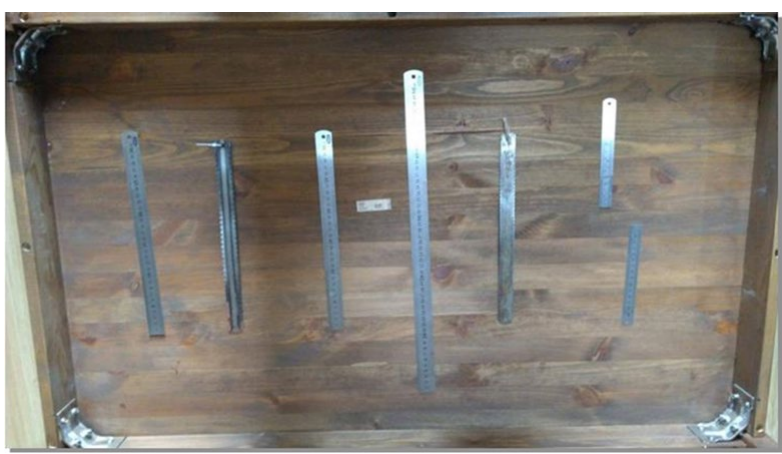

FIGURE 6. Locations of ferromagnetic materials placed in the first test system with the size of $90 \times 60 \mathrm{~cm}$ (bottom view).

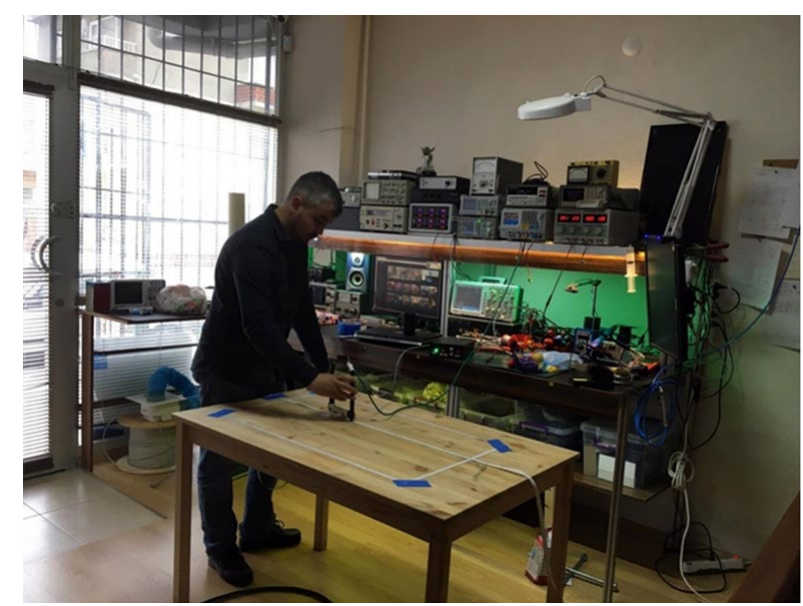

FIGURE 7. MFL measurement performed on the first test system with the size of $90 \times 60 \mathrm{~cm}$.

The map obtained as a result of the MFL measurements on the first test system is shown in Figure 8. The locations and geometries of 7 ferromagnetic materials were detected by the produced magnetic flux leakage device.
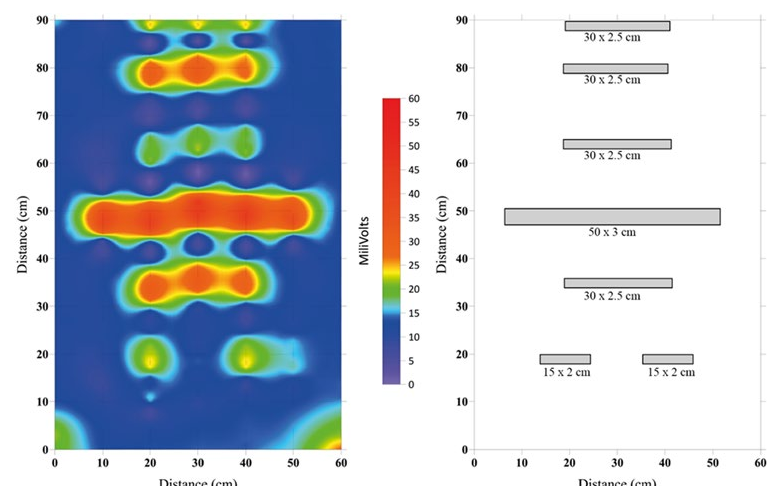

FigURE 8. Signal map of ferromagnetic materials obtained by magnetic flux leakage (MFL) device.

\subsection{Test system 2}

The second test system used 3 ferromagnetic materials within an $80 \times 50 \mathrm{~cm}$ area as shown in 
Figure 9. The depth of ferromagnetic materials are at $2 \mathrm{~cm}$ from the top of the test systems 2.

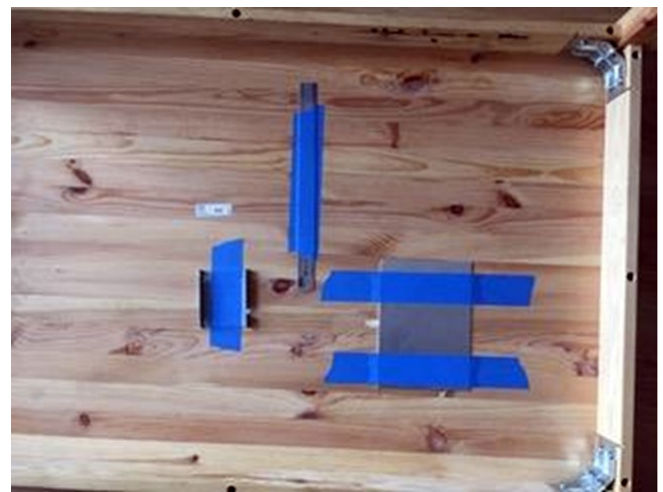

FigURE 9. Locations of ferromagnetic materials placed in the second test system with the size of $85 \times 50 \mathrm{~cm}$ (bottom view).

The profile interval in the second test system was $10 \mathrm{~cm}$ and measurements were performed with the MFL device at $1 \mathrm{~cm}$ point intervals.

The map obtained as a result of MFL measurements completed for the second test system is shown in Figure 10. Locations and geometries of 3 ferromagnetic materials were identified by the magnetic flux leakage device.
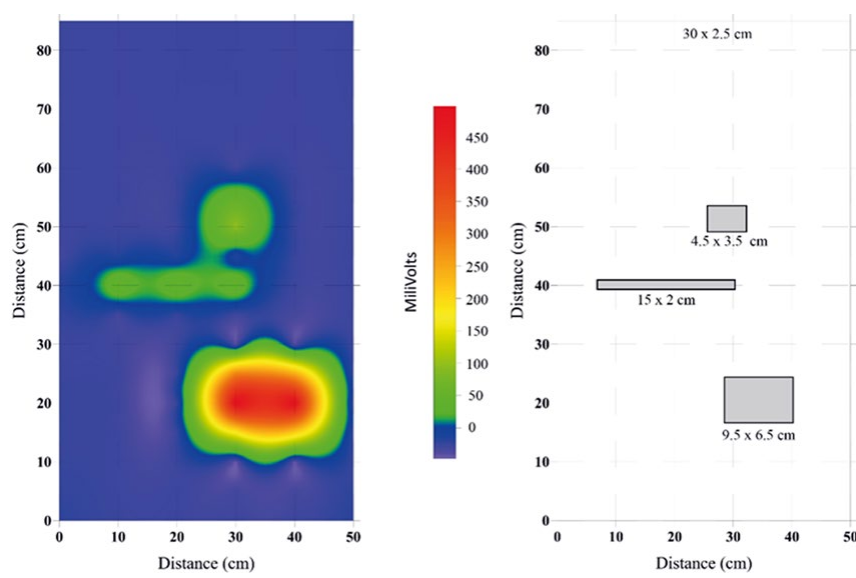

FIGURE 10. Signal map of ferromagnetic materials obtained by magnetic flux leakage (MFL) device.

\subsection{Test system 3}

The third test system placed 7 rebar elements at 20 $\mathrm{cm}$ intervals within an $80 \times 150 \mathrm{~cm}$ area as shown in Figure 11. The depth of reinforcements are at $10 \mathrm{~cm}$ from the top of the test system 3 .

The profile intervals for the third system were $10 \mathrm{~cm}$ and measurements were made with the magnetic flux leakage device at point intervals of $5 \mathrm{~cm}$ (Figure 12).

The map obtained with the MFL measurements completed in the third test system is shown in

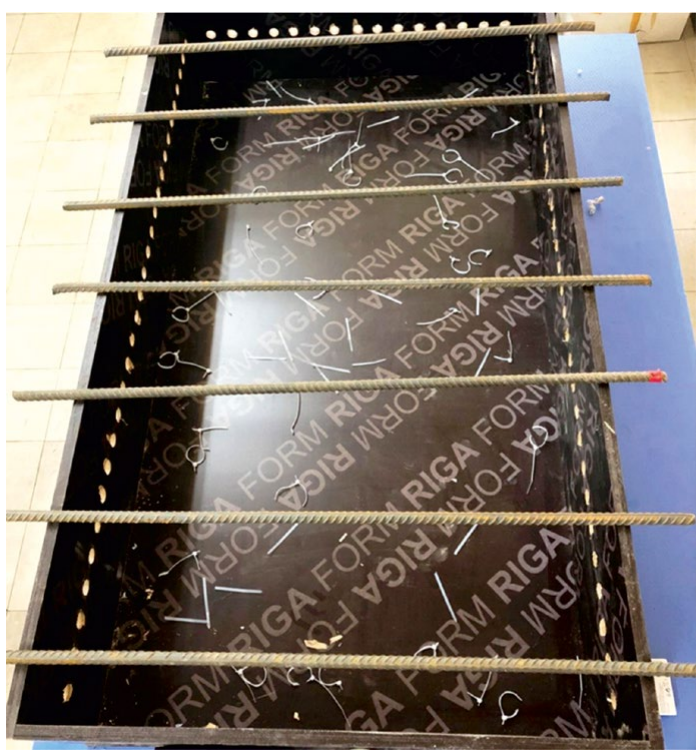

FIGURE 11. Locations of the construction steel placed in the third test system with the size of $80 \times 150 \mathrm{~cm}$.

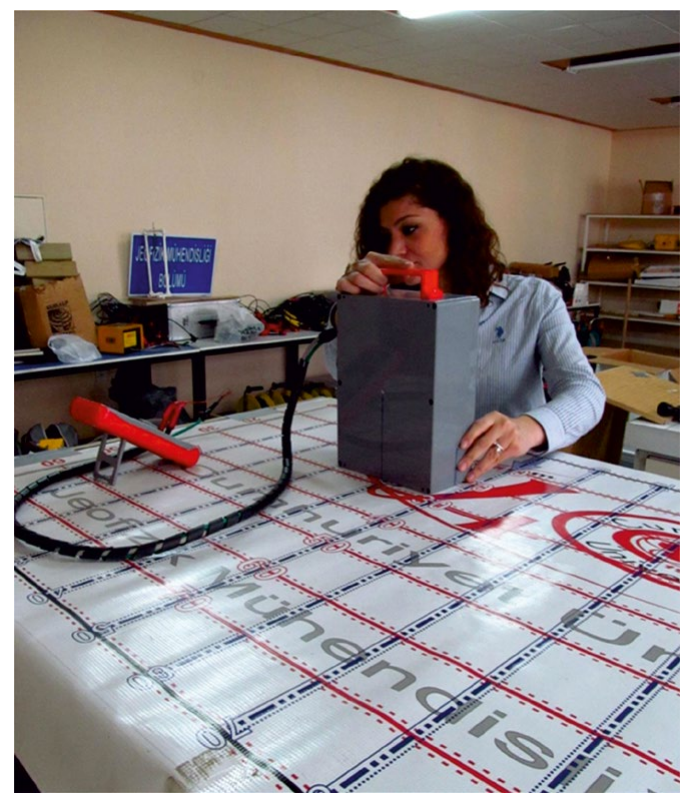

FIGURE 12. MFL measurement performed on the third test system with the size of $80 \times 150 \mathrm{~cm}$.

Figure 13. Locations and geometries of 7 rebars were identified by the magnetic flux leakage device.

\subsection{Test system 4}

The fourth test system placed 4 rebar elements at $20 \mathrm{~cm}$ intervals in the $\mathrm{X}$ direction and 7 rebars at $20 \mathrm{~cm}$ intervals in $\mathrm{Y}$ direction within an $80 \times$ $150 \mathrm{~cm}$ area as shown in Figure 14. The depth of reinforcements are at $10 \mathrm{~cm}$ from the top of the test system 4. 


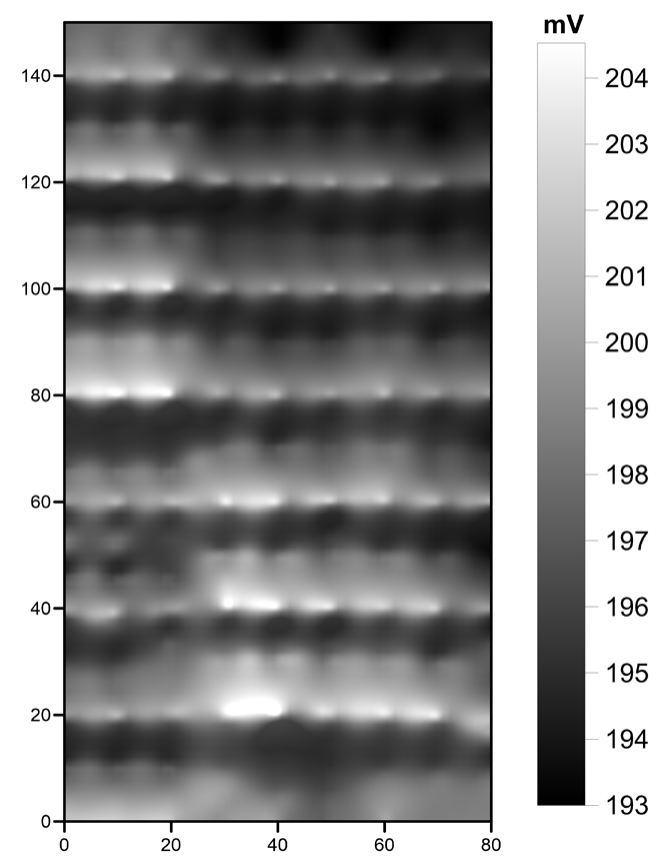

FIGURE 13. Signal map of construction steels obtained by magnetic flux leakage (MFL) device.

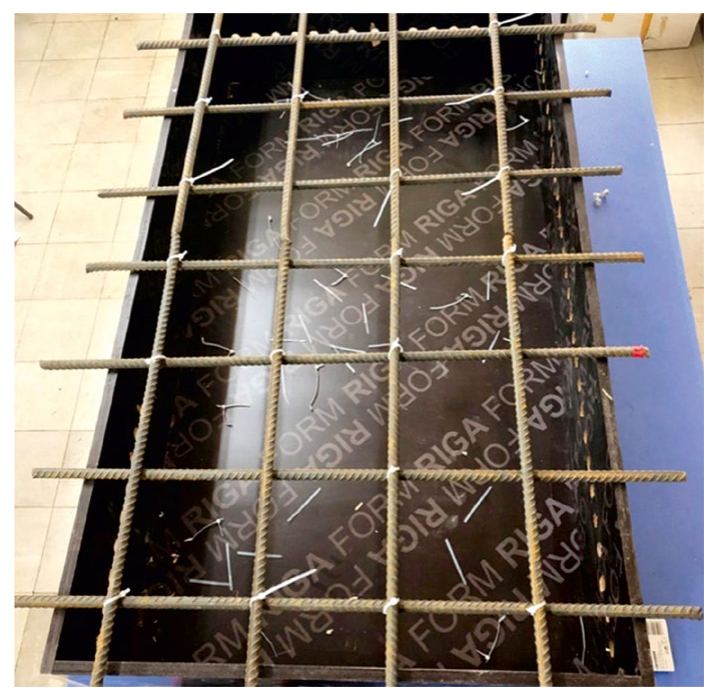

FIGURE 14. Locations of the construction steel placed in the fourth test system with the size of $80 \times 150 \mathrm{~cm}$.

Measurements were performed with a magnetic flux leakage device at profile intervals of 10 $\mathrm{cm}$ and point intervals of $5 \mathrm{~cm}$ for the fourth test system.

The map obtained from MFL measurements completed in the fourth test setup is shown in Figure 15. 4 rebar at $20 \mathrm{~cm}$ intervals in the $X$ direction and 7 rebar located at $20 \mathrm{~cm}$ intervals in the $\mathrm{Y}$ direction were identified by the magnetic flux leakage device.

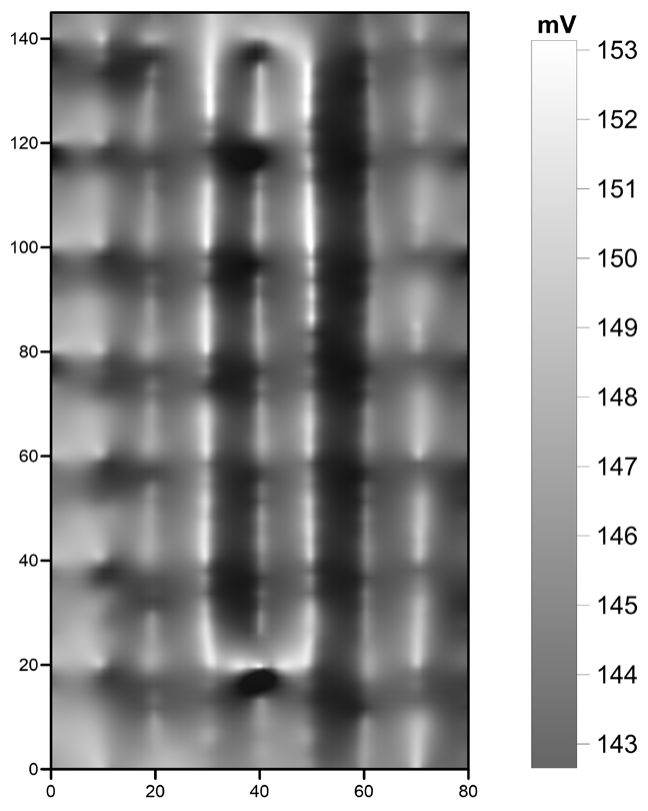

FIGURE 15. Signal map of construction steels obtained by magnetic flux leakage (MFL) device.

\section{CONCLUSIONS}

There are several studies performed with the MFL method. The majority of these studies use the MFL method to determine defects in pipelines and rail systems. Another area of use is about detection of corrosion occurring in the structural elements. In this study, device for the nondestructive test technique of MFL method was produced and used for detection of reinforcement comprising structural elements in buildings. Thus, our results are showed that the MFL method can be used to detection reinforcement in addition to previous studies. The produced magnetic flux leakage device comprised a total of three sections. The first section included an oscillator with $300 \mathrm{~Hz}$ frequency signal output and amplifier circuits to increase amplitude. This section included a Tx (transmitter) comprising a U-core coil creating the primary magnetic field. The second section included a Rx (receiver) detecting the secondary magnetic field induced within ferromagnetic material and the third section was a voltmeter measuring the signal coming from the receiver. The magnetic flux leakage device was tested in 4 different systems. Thus, within the scope of this study, the magnetic flux leakage device provided successful data for determining rebar in reinforced concrete structures.

\section{ACKNOWLEDGEMENTS}

This work is supported by the Scientific Research Project Fund of Sivas Cumhuriyet University under the project number M-516. 


\section{AUTHOR CONTRIBUTIONS:}

Conceptualization: Ö. Bektaş, Y.C. Kurban, B. Özboylan. Methodology: Y.C. Kurban. Project administration: Ö. Bektaş. Supervision: Ö. Bektaş. Visualization: Y.C. Kurban, B. Özboylan. Writing, review \& editing: Ö. Bektaş, Y.C. Kurban, B. Ozboylan.

\section{REFERENCES}

1. Karakus, M.; Tütmez, B. (2006) Fuzzy and multiple regression modelling for evaluation of intact rock strength based on point load, Schmidt hammer and sonic velocity. Rock Mech. Rock Eng. 39 [1], 45-57. https://doi.org/10.1007/ s00603-005-0050-y.

2. Vasconcelos, G.; Lourenço, P.B.; Alves, C.A.; Pamplona, J. (2007) Prediction of the mechanical properties of granites by ultrasonic pulse velocity and Schmidt hammer hardness. North American Masonry Conference June 3-7 Missouri USA.

3. Sharma, P.K.; Singh, T.N. (2008) A correlation between P-wave velocity, impact strength index, slake durability index and uniaxial compressive strength. B. Eng. Geol. Environ. 67 [1], 17-22. https://doi.org/10.1007/s10064-007-0109-y.

4. Kurtuluş, C.; Irmak, T.S.; Sertçelik, I. (2010) Physical and mechanical properties of Gokceada: Imbros (NE Aegean Sea) island andesites. B. Eng. Geol. Environ. 69 [2], 321324. https://doi.org/10.1007/s10064-010-0270-6.

5. Sharma, P.K.; Khandelwal, M.; Singh, T.N. (2011) A correlation between Schmidt hammer rebound numbers with impact Strength index, slake durability index and P-wave velocity. Int. J. Earth Sci. 100 [1], 189-195. https://doi. org/10.1007/s00531-009-0506-5.

6. Fort, R.; de Buergo, M.A.; Perez-Monserrat, E.M. (2013) Non-destructive testing for the assessment of granite decay in heritage structures compared to quarry stone. Int. J. Rock. Mech. Min. 61, 296-305. https://doi.org/10.1016/j. ijrmms.2012.12.048.

7. Pamuk, E.; Büyüksaraç, A. (2017) Investigation of strength characteristics of natural Stones in Ürgüp (Nevşehir/Turkey). Bitlis Eren Univ. J. Sci. Technol. 7 [2], 74-79. https://doi. org/10.17678/beuscitech.305653.

8. Ișık, E.; Bakıș, A.; Akıllı, A.; Hattaoğlu, F. (2015) Usability of ahlat stone as aggregate in reactive powder concrete. Int. J. App. Sci. Eng. Res. 4 [4], 507-514.

9. Işık, E.; Büyüksaraç, A.; Avşar, E.; Kuluöztürk, M.F.; Günay, M. (2020) Characteristics and properties of Bitlis ignimbrites and their environmental implications. Mater. Construcc. 70 [338], e214. https://doi.org/10.3989/mc.2020.06519.

10. Karahan, S.; Büyüksarac, A.; Isık, E. (2020) The Relationship between concrete strengths obtained by destructive and nondestructive methods. Iran. J. Sci. Technol. Transact. Civ.
Engineer. 44, 91-105. https://doi.org/10.1007/s40996-01900334-3.

11. Okolo, K. W. (2018) Modelling and experimental investigation of magnetic flux leakage distribution for hairline crack detection and characterization. Wolfson Centre for Magnetics School of Engineering, Cardiff University. (PhD Thesis).

12. Rao, B.P.C. (2012) Magnetic flux leakage technique. J. Non Destr. Test. Eval. 11 [3], 7-17.

13. Li, L.; Huang, S.; Zheng, P.; Shi, K. (2002) Evaluation of surface cracks using magnetic flux leakage testing. J. Mater. Sci. Technol. 18 [4], 319-321.

14. Ramirez, A.R.; Mason, J.S.D.; Pearson, N. (2009) Experimental study to differentiate between top and bottom defects for MFL tank floor inspections. NDT\&E Intern. 42 [1], 16-21. https://doi.org/10.1016/j.ndteint.2008.08.005.

15. Sun, Y.; Kang, Y. (2010) A new MFL principle and method based on near-zero background magnetic field. NDT\&E Intern. 43 [4], 348-353. https://doi.org/10.1016/j. ndteint.2010.01.005.

16. Tsukada, K.; Yoshioka, M.; Kiwa; T.; Hirano, Y. (2011) A magnetic flux leakage method using a magnetoresistive sensor for non destructive evaluation of spot welds. NDT\&E Intern. 44 [1], 101-105. https://doi.org/10.1016/j. ndteint.2010.09.012

17. Göktepe, M.; Perin, D. (2012) Inspection of rebars in concrete blocks. Int. J. Appl. Electromagn. Mech. 38 [2-3], 65-78. https://doi.org/10.3233/JAE-2012-1409.

18. Loa, C.C.H.; Nakagawa, N. (2013) Evaluation of eddy current and magnetic techniques for inspecting rebars in bridge barrierrails. AIP Conf. Proc. 1511, 1371. https://doi.org/10.1063/1.4789202.

19. Shi, Y.; Zhang, C.; Li, R.; Cai, M.; Jia, G. (2015) Theory and application of magnetic flux leakage pipeline detection. Sensors. 15 [2], 31036-31055. https://doi.org/10.3390/s151229845.

20. Wu, D.; Liu, Z.; Wang, X.; Su, L. (2017) Composite magnetic flux leakage detection method for pipelines using alternating magnetic field excitation. NDT\&E Intern. 91, 148-155. https://doi.org/10.1016/j.ndteint.2017.07.002.

21. Wilcke, M.; Walther, A.; Szielasko, K.; Youssef, S. (2018) The MFL technique - Basic application for PT cable break detection in concrete structures. MATEC Web of Conferences 199, 06013 ICCRRR 2018.

22. Antipov, A.G.; Markov, A.A. (2018) A new MFL principle and method based on near-zero background magnetic field. NDT\&E Intern. 98, 177-185. https://doi.org/10.1016/j. ndteint.2018.04.011.

23. Sadr, A.; Okhovat, R.S. (2016) Extracting the region of interest from MFL signals. Turk. J. Elec. Eng. Comp. Sci. 24 , 427-434. https://doi.org/10.3906/elk-1305-70.

24. Myakushev, K.; Slesarev, D.; Sukhorukov, D. (2018) Magnetic flux leakage (MFL) method for nondestructive testing of prestressed steel reinforcement strands. 12th European Conference on Non-Destructive Testing (ECNDT 2018), Gothenburg 2018, June 11-15 (ECNDT 2018). 